\title{
Identifikasi Fitoplankton di Perairan yang Tercemar Lumpur Lapindo, Porong Sidoarjo
}

\author{
NOFADILA Q. A'AYUN, TERRY A. P. PERDANA*, \\ PUTRO AJI PRAMONO, AINUN NIKMATI LAILY
}

Universitas Islam Negeri Maulana Malik Ibrahim Malang

\author{
Jl. Gajayana 50, Malang, Indonesia
}

*email: terryperdana@gmail.com

Manuscript received: 17 Desember 2014 Revision accepted: 27 Januari 2015

\begin{abstract}
Some waters are experiencing errors processing till that waters to be waste disposal which resulted in the loss of existing potential, affect water quality and further on the presence of organisms present in the water, especially plankton (phytoplankton) which is the first organisms respond to changes in water quality. One of the pollutants in the water is mud Lapo in Porong, Sidoarjo. This research aims to identify phytoplankton in polluted waters, lapindo mud Porong, Sidoarjo. The method used is the method description. The analysis of samples carried out in the laboratory of Ecology Department of Biology, Faculty of Science and Technology, Maulana Malik Ibrahim State Islamic University Malang . The results of this research was the discovery of 18 species of phytoplankton of the class Chlorophyceae, Trebouxiophyceae, Euglenophyceae, Bacillariophyceae, and from the Division Cyanophyta genus Oscillatoria and Chrococcus.
\end{abstract}

Keywords: Identification, Phytoplankton, Porong

\section{LATAR BELAKANG}

Wilayah pesisir merupakan daerah pertemuan antara daratan dan lautan. Wilayah ini sangat kompleks karena dipengaruhi oleh berbagai kegiatan yang ada diluar maupun di dalam wilayah itu sendiri. Kesalahan pengelolaan wilayah pesisir menjadikan wilayah ini sebagai tempat pembuangan limbah yang dapat mengakibatkan hilangnya potensi yang ada. Masuknya bahan organik ke pesisir ini cepat atau lambat akan dapat memengaruhi kualitas air, yang selanjutnya berpengaruh pada keberadaan organisme yang ada di perairan, khususnya plankton yang merupakan organisme pertama yang merespon perubahan kualitas air tersebut (Abida, 2010). Kualitas air yang baik sangat penting untuk mendukung kehidupan biota air. Kondisi kualitas air menentukan ketersediaan pakan alami bagi ikan seperti plankton, bentos dan tumbuhan air (Astuti, 2009).

Sungai Porong, Sidoarjo merupakan salah satu muara yang terkena aliran lumpur PT. Lapindo Berantas. Pengelolaan pembuangan lumpur yang kurang baik dapat mengakibatkan bahan unsur organik dan anorganik terbawa arus dan dapat menghilangkan potensi yang ada pada sungai. Selain itu, disekitar kawasan sungai porong banyak terdapat lahan pertambakan yang memanfaatkan air sungai sebagai media budidaya (Abida, 2010).

Air sungai kecil dan parit-parit yang ada disekitar tanggul pembuangan lumpur lapindo merupakan daerah yang teraliri oleh Sungai Porong. Apabila air dalam Sungai Porong tersebut mengandung limbah lumpur lapindo, maka sungai dan parit yang teraliri sungai porong akan sedikit banyak mengandung bahan limbah lumpur lapindo tersebut. Fitoplankton merupakan organisme yang berukuran sangat kecil yang hidup di daerah yang mengandung air. Habitat yang tercemar akan mengakibatkan pertumbuhan dan perkembangan spesies mikroskopik ini menjadi terganggu. Hal tersebut akan mengakibatkan ketidakseimbangan ekosistem.

Menurut Soeprobowati (2011) fitoplankton adalah organisme mikroskopik yang hidupnya melayang dekat dengan permukaan air. Hal ini didasarkan pada fakta bahwa secara umum, fitoplankton mempunyai peranan penting sebagai produser primer perairan, mempunyai siklus hidup yang pendek, dan banyak spesiesnya yang sensitif terhadap perubahan lingkungan.

Keberadaan fitoplankton dapat dijadikan sebagai bioindikator adanya perubahan lingkungan perairan yang disebabkan oleh ketidakseimbangan suatu ekosistem akibat pencemaran (Oxborough dan Baker, 1997; Ekwu dan Sikoki, 2006 dalam Fachrul, 2008). Sachlan (1982 dalam Utomo 2011) menyebutkan bahwa mikro algae plankton merupakan parameter biologi yang erat hubungannya dengan zat hara. Menurut Lancar \& Krake (2002 dalam Utomo 2011) kelimpahan fitoplankton dapat mengasimilasi sebagian besar zat hara dari perairan. Kelimpahan plankton di suatu perairan akan dipengaruhi oleh parameter lingkungan termasuk kualitas perairan dan fisiologi. Kelimpahan dan komposisi plankton dapat berubah pada berbagai tingkatan sebagai respon terhadap perubahan kondisi lingkungan fisik, biologi dan kimiawi perairan. Ada tiga faktor utama yang memengaruhi respon pertumbuhan plankton yaitu suhu, cahaya dan nutrien. Bila suhu, cahaya, dan nutrien dalam kondisi yang 
optimum maka plankton akan tumbuh dengan pesat (Vithanage, 2009 dalam Utomo, 2011).

Komposisi dan kelimpahan tertentu dari fitoplankton pada suatu perairan sangat berperan sebagai makanan alami pada tropik level diatasnya, juga berperan sebagai penyedia oksigen dalam perairan (Abida, 2010). Fitoplankton adalah organisme perairan yang sangat penting sebagai produsen utama pada rantai makanan (Rozirwan, 2010).

Fitoplankton sebagai tumbuhan yang mengandung pigmen klorofil mampu melaksanakan reaksi fotosintesis dimana air dan karbondioksida dengan adanya sinar surya dan garam-garam hara dapat menghasilkan senyawa organik seperti karbohidrat (Thoha, 2011). Fitoplankton lebih banyak dijumpai pada zona fotik (badan air yang masih dapat ditembus sinar matahari). Hasil fotosintesis oleh fitoplankton dimanfaatkan sebagai sumber energi oleh organisme pada tingkatan trofik selanjutnya (Soeprobowati, 2011).

Pengelolaan habitat fitoplankton diperlukan untuk menunjang pertumbuhannya secara maksimal yang akan memberikan banyak manfaat bagi keseimbangan ekosistem. Konservasi merupakan salah satu cara yang dapat dilakukan untuk mengembalikan fungsi asli habitat tersebut.

Adanya masukan bahan-bahan organik dan buangan lumpur pada daerah perairan yang ada disekitar lumpur lapindo akan meningkatkan kekeruhan dan mencemari daerah tersebut. Menurut Abida (2010) hal tersebut akan memengaruhi keanekaragaman fitoplankton di dalamnya karena ketersediaan unsur hara yang tersebar tidak merata dan kurangnya penetrasi cahaya. Berdasarkan uraian tersebut maka perlu dilakukan penelitian terkait keanekaragaman fitoplankton setelah pembuangan lumpur lapindo di daerah perairan dekat tanggul lumpur lapindo. Penelitian ini bertujuan untuk mengetahui keanekaragaman fitoplankton di daerah perairan yang dekat dengan tanggul lumpur lapindo, Porong, Sidoarjo.

\section{METODE}

\section{Waktu dan Tempat}

Penelitian dilakukan pada 27 September-3 Oktober tahun 2014. Sampel diambil dari perairan yang tercemar lumpur lapindo, Porong Sidoarjo. Identifikasi dilakukan di Laboratorium Ekologi Jurusan Biologi, Fakultas Sains dan Teknologi, Universitas Islam Negeri Maulana Malik Ibrahim Malang.

\section{Alat dan Bahan}

Alat dan bahan yang digunakan adalah botol, sprayer, akuades $500 \mathrm{~mL}$, plankton net kerapatan 200 mesh, corong gelas, beaker glass, ph meter, termometer, lux meter, mikroskop binokuler, pipet tetes, deck glass dan cover glass.

\section{Cara Kerja}

Metode yang digunakan dalam penelitian ini adalah metode deskriptif. Penelitian ini dilakukan pada tiga stasiun pengambilan sampel. Langkah kerja dalam penelitian ini yang pertama adalah pengambilan sampel yang dilakukan menggunakan botol ukuran $1500 \mathrm{ml}$ di tiga stasiun berbeda yang berada di dekat tanggul yaitu, parit kecil, sungai, dan bekas tambak bandeng serta disaring menggunakan plankton net dengan kerapatan 200 mesh. Selanjutnya sampel diamati menggunakan mikroskop binokuler dan diidentifikasi spesies fitoplankton hasil pengamatan berdasarkan karakteristik bentuk dan warnanya.

\section{HASIL DAN PEMBAHASAN}

\section{Deskripsi Stasiun}

Stasiun I merupakan parit kecil yang dialiri oleh lumpur Lapindo di Porong Sidoarjo. Parit kecil ini memiliki Ph 7 dengan suhu air $29^{\circ} \mathrm{C}$, nampak berwarna abu-abu kecokelatan. Stasiun II adalah sungai yang dialiri lumpur Lapindo yang memiliki $\mathrm{Ph}$ dan suhu yang sama seperti stasiun pertama, nampak berwarna cokelat keabu-abuan. Sedangkan stasiun III merupakan bekas tambak bandeng yang berair asin dengan $\mathrm{Ph} 7$ dan suhu $29^{\circ} \mathrm{C}$ dan teraliri oleh lumpur namun kuantitasnya lebih sedikit dari stasiun I dan II, memiliki warna hijau muda. Ketiga stasiun memiliki intensitas cahaya yang sama yaitu 500x100 lux

\section{Hasil}

Tabel 1. Spesies fitoplankton muara sungai porong, Sidoarjo

\begin{tabular}{lccc}
\multicolumn{1}{c}{ Spesies } & $\begin{array}{c}\text { Stasiun } \\
\text { I }\end{array}$ & $\begin{array}{c}\text { Stasiun } \\
\text { II }\end{array}$ & $\begin{array}{c}\text { Stasiun } \\
\text { III }\end{array}$ \\
\hline Oscillatoria sp. & $\sqrt{ }$ & & \\
Microcystis sp. & $\sqrt{ }$ & & \\
Chrococcus sp. & $\sqrt{ }$ & & \\
Melosira sp. & $\sqrt{ }$ & & \\
Surirella sp. & $\sqrt{ }$ & & \\
Coracina sp. & & $\sqrt{ }$ & \\
Ulothrix sp. & & $\sqrt{ }$ & \\
Zygnema sp. & & $\sqrt{ }$ & \\
Calcarea sp. & $\sqrt{ }$ & \\
Euglena sp & & $\sqrt{ }$ & \\
Navicula sp. & & $\sqrt{ }$ & $\sqrt{ }$ \\
Cyclotella sp. & & $\sqrt{ }$ & \\
Synendra sp. & & $\sqrt{ }$ & \\
Sp 1 (Euglenophyceae) & & & $\sqrt{ }$ \\
Microthamnion sp. & & & $\sqrt{ }$ \\
Sp 2 (Chlorophyta) & & & $\sqrt{ }$ \\
Sp 3 (Chlorophyta) & & & $\sqrt{ }$ \\
Sp 4 (Chlorophyta) & & & \\
\hline
\end{tabular}

Identifikasi fitoplankton di perairan yang tercemar lumpur lapindo, Porong Sidoarjo pada tiga stasiun ditemukan spesies-spesies dari kelas Chlorophyceae, Euglenophyceae, Bacillariophyceae, dan 2 marga dari divisi Cyanophyta yakni Oscillatoria dan Chrococcus. Pada stasiun I, ditemukan kedua marga dari Cyanophyta yang telah disebutkan sebelumnya yaitu Oscillatoria dan Chrococcus. Ditemukan pula fitoplankton dari kelas Bacillariophyceae dari marga Melosira dan Surirella, serta dari kelas chlorophyceae marga pandorina. 
Stasiun II, ditemukan fitoplankton dari kelas Chlorophyceae marga Coracina, Ulothrix, Zygnema, dan marga Calcarea yang melimpah. Ditemukan pula marga Euglena dari kelas Euglenophyceae dan tiga spesies dari kelas Bacillariophyceae bermarga Navicula, Cyclotella, dan Synendra.

Stasiun III ditemukan fitoplankton kelas Euglenophyceae dari divisi Euglenophyta yang melimpah, begitu juga dengan kelas Trebouxiophyceae marga Microthamnion yang banyak ditemukan pula. Fitoplankton lain yang ditemukan dari kelas Bacillariophyceae (diatom) marga Navicula serta lima spesies yang menampakkan warna hijau dominan yang diduga merupakan divisi Chlorophyta.

\section{Pembahasan}

Spesies dengan kelas Chlorophyceae, Basillarophyceae, Euglenophyceae, dan dari divisi Cyanophyta marga Oscillatoria dan Chrococcus ditemukan dalam perairan yang tercemar lumpur lapindo, Porong Sidoarjo pada suhu $29^{\circ} \mathrm{C}$. Spesies-spesies ini memang dapat ditemukan pada suhu tersebut, hal itu sesuai dengan yang disebutkan Haslan (1995) dalam Effendi (2013) bahwa kisaran suhu optimal bagi pertumbuhan fitoplankton adalah $20^{\circ} \mathrm{C}-30^{\circ} \mathrm{C}$.

Data spesies di atas ditemukan dalam perairan yang tercemar lumpur lapindo, Porong Sidoarjo pada $\mathrm{Ph} 7$ di setiap stasiun. Stasiun I dan II berair tawar sedangkan Stasiun III berair asin. Stasiun III ditemukan dominasi kelas Euglenophyceae dan Trebouxiophyceae dengan marga Microthamnion yang melimpah. Sulisetijono (2009) menyebutkan bahwa Euglenophyta dapat hidup di air tawar dan beberapa di air laut terutama pada tempat yang banyak mengandung bahan organik sedangkan Microthamnion dapat hidup di air tawar. Hal ini tidak sesuai dengan keadaan air pada stasiun III yang berair asin. Namun, Menurut Effendi (2003) Ph optimum untuk pertubumbuhan/habitat fitoplankton adalah 7-8,5. Sehingga kemungkinan Microthamnion dan spesiesspesies dari Eugenophyceae dapat hidup di stasiun III.

Hasil penelitian keragaman fitoplankton di perairan yang tercemar lumpur lapindo ini tidak menunjukkan adanya dominasi dari kelas Bacillariophyceae, akan tetapi pada setiap stasiun terdapat spesies yang termasuk kelas ini. Hasil tersebut bertentangan dengan hasil penelitian Abida (2010) Damar (2003); Abida (2008) bahwa genera fitoplankton dari kelas Bacillariophyceae dan Dinophyceae ditemukan mendominasi karena fitoplank ton dari kedua kelas tersebut merupakan anggota utama fitoplankton yang terdapat di seluruh bagian perairan laut, baik perairan pantai maupun perairan oseanik.Ini sebab sampel adalah bukan dari air laut, walaupun pada stasiun III berair asin.

Keanekaragaman spesies fitoplankton dianggap rendah sebab hanya ditemukan 18 spesies oleh peneliti dari tiga stasiun dengan pengulangan tiga kali pengamatan di bawah mikroskop dari tiap sampel di tiga stasiun tersebut. Menurut Hasil penelitian Abida (2008) di perairan pantai selat Madura kabupaten Bangkalan menunjukkan bahwa kolam perairan yang teraduk akibat resuspensi sedimen mempunyai nilai kekeruhan yang tinggi sehingga ada keterbatasan cahaya dikolam perairan dalam mendukung proses fotosintesis dan mempengaruhi sebaran fitoplankton di kolam perairan. Sedangkan kemungkinan perairan yang tercemar lumpur lapindo juga banyak endapan lumpur yang berpengaruh terhadap kelimpahan keanekaragaman fitoplankton.

\section{KESIMPULAN}

Hasil penelitian menunjukkan bahwa dalam sampel yang diambil dari perairan yang tercemar lumpur lapindo, Porong Sidoarjo terdapat spesies-spesies fitoplankton dari Kelas Euglenophyceae, Chlorophyceae, Trebouxiophyceae, Bacillariophyceae, dan Divisi Cyanophyta marga Chrococcus dan Oscillatoria.

Penelitian ini mengukur suhu air, $\mathrm{Ph}$, dan intensitas cahaya di perairan yang tercemar lumpur Lapindo, Porong Sidoarjo. Perlu dilakukan penelitian lebih lanjut menyangkut indikator yang diukur dan unsur hara terkait dengan keadaan hidrodinamika perairan dalam menunjang keberadaan fitoplankton sebagai produsen, sehingga data yang didapat akan lebih akurat.

\section{UCAPAN TERIMA KASIH}

Diucapkan terimakasih kepada saudari Shubriyah, mahasiswi Biologi UIN Malang angkatan 2013 yang turut membantu dalam penelitian ini, serta semua pihak yang mendukung dan turut membantu terselesaikannya penelitian ini.

\section{DAFTAR PUSTAKA}

A. Damar. (n.d.). Effects of Enrichment on Nutrient Dynamics, Phytoplankton Dynamics and Productivity in Indonesian Tropical Water: A Comparison Between Jakarta Bay, Lampung Bay and Semangka Bay. Ph.D Dissertation Christian Albrechts. University. Kiel.Germany.

Abida, I. W., (2008). Produktivitas Primer Fitoplankton dan Keterkaitannya dengan Intensitas Cahaya dan Ketersediaan Nutrien Pada Perairan Selat Madura Kabupaten bangkalan. Prosiding Senta ITS, Surabaya.

Abida, I. W., (2010). Struktur Komunitas dan Kelimpahan Fitoplankton di Perairan Muara Sungai Porong Sidoarjo. Jurnal Kelautan, 3, 36-40.

Astuti, L. P., Waras, A., Satria, H. (n.d.). Kualitas Air dan Kelimpahan Plankton di Danau Sentani, Kabupaten Jayapura. Jurnal Perikanan, 9, 66-77.

Effendi H. (n.d.). Telaah Kualitas Air Bagi Pengelolaan Sumberdaya dan Lingkungan Perairan. Yogyakarta: Kasinius.

Fachrul, Melati F., Setijati H. E., \& Monika Wulandari. (2008). Komposisi dan Model Kemelimpahan Fitoplankton di 
Perairan Sungai Ciliwung, Jakarta. Biodiversitas, 9, 296300.

Rozirwan. (2010). Identifikasi Morfologi Dinoflagelata dari fenomena Ledakan Populasi Alga di Pantai Lido, Johor Bahru Malaysia. Jurnal Penelitian Sains, 13, 53-56.

Soeprobowati, T. R., \& Suedy, S. W. A. (2011). Komunitas Fitoplankton Danau Rawapening, 19, 19-30.
Sulisetjono. (2009). Bahan Serahan Alga. Malang: UIN Press.

Thoha, H. \& Amri, K. (2011). Komposisi dan Kelimpahan Fitoplankton di Perairan Kalimantan Selatan. Oseanologi Dan Limnologi Di Indonesia, 37, 371-382. 